\title{
Application value of thromboelastography in perioperative clinical blood transfusion and its effect on the outcome of patient
}

\author{
HAIYAN SHI ${ }^{1}$, BO SHI $^{2}, \mathrm{JUN} \mathrm{LU}^{3}$, LINGLING WU ${ }^{4}$ and GUANG SUN ${ }^{5}$ \\ Departments of ${ }^{1}$ Blood Transfusion and ${ }^{2}$ Neurology, The First Hospital of Zibo, Zibo, Shandong 255000; \\ ${ }^{3}$ Department of Blood Transfusion, The Sixth People's Hospital Affiliated to Shanghai Jiaotong University, \\ Shanghai 200233; ${ }^{4}$ Department of Blood Transfusion, Quanzhou First Hospital Affiliated to Medical University of Fujian, \\ Quanzhou, Fujian 362000; ${ }^{5}$ Department of Intensive Care Unit, Central Hospital of Zibo, Zibo, Shandong 255000, P.R. China
}

Received October 15, 2018; Accepted February 20, 2019

DOI: $10.3892 / \mathrm{etm} .2019 .7333$

\begin{abstract}
Application value of thromboelastography (TEG) in perioperative clinical blood transfusion and its effect on the outcome of patient were investigated. Seventy-four patients, admitted to The Surgical Department of the First Hospital of Zibo from March 2015 to March 2018, were selected for this study. Among them, 34 patients took only the traditional coagulation function testing method as the blood transfusion guide during the perioperative period and they were regarded as the control group. The other 40 patients used TEG as the blood transfusion guide during the perioperative period, and they were regarded as the TEG group. The coagulation function indicators in $2 \mathrm{~h}$ before the operation and in $24 \mathrm{~h}$ after the operation, the transfusion amount and blood loss during the operation, the condition of the blood transfusion during the perioperative period, the occurrence rate of the postoperative rebleeding, the length of hospital stay and mortality of the patients in the two groups were compared. The coagulation function indicators of the patients in the two groups in $2 \mathrm{~h}$ before the operation and in $24 \mathrm{~h}$ after the operation showed that there was no significant difference between the two groups $(\mathrm{P}>0.050)$. However, APTT and Pt of the patients in the two groups both increased when compared with those before the treatment $(\mathrm{P}<0.050)$ and $\mathrm{Hb}, \mathrm{Hct}$, Plt and Fib all decreased $(\mathrm{P}<0.050)$. The suspended erythrocytes, Plt, fibrinogen and plasma in the TEG group were both significantly lower than those in the control group $(\mathrm{P}<0.001)$. Compared with the traditional coagulation function test, TEG was more accurate for estimating the coagulation function of patient and was more suitable for estimating the condition of blood transfusion of
\end{abstract}

Correspondence to: Dr Guang Sun, Department of Intensive Care Unit, Central Hospital of Zibo, 4 Gongqingtuan West Road, Zhangdian, Zibo, Shandong 255000, P.R. China

E-mail: qekuac@163.com

Key words: thromboelastography, perioperative period, blood transfusion, coagulation function patient in the perioperative period; also, it could shorten the recovery period of patient and it is worthwhile to promote it in the clinic.

\section{Introduction}

During the process of surgery, perioperative massive hemorrhage is also a major problem needed to be solved first in the clinic (1). Most patients will cause a disorder of coagulation function due to the traumatic invasive surgery (2). Moreover, the patient is extremely prone to have massive hemorrhage, which endangers the patient's life and health (3). In clinic, a patient who is in the perioperative period is required to provide timely blood products to supplement the normal blood circulation in the patient (4). When facing the problem how to choose the most appropriate opportunity of blood transfusion, the most traditional method in clinic is to estimate whether the patient's coagulation function and erythrocyte function are abnormal or not (5). However, at present, with the continuous increase of difficult diseases, the defects of traditional detection methods are becoming more and more obvious. For example, the timeliness and effectiveness of the detection are poor, and real-time blood function detection cannot be achieved (6). When facing the situation of sudden massive hemorrhage, an effective prejudgment cannot be made, which may lead to excessive blood loss and threaten patient's life (7). Therefore, research on how to detect the coagulation function of the patient in real-time in clinic is urgent and a major breakthrough is required.

With the continuous development of modern medical technology, thromboelastography (TEG) was developed. TEG can draw changeable images according to the dynamic changes of patient's coagulation function and can accurately and integrally estimate the general situation of coagulation function and the formation of thrombus of patient, and the monitoring is convenient and fast $(8,9)$. Since 2015 , the surgical department of our hospital have widely used TEG as the judgment indicator for the perioperative blood transfusion of patients, and now enough research cases have been accumulated. The value of TEG in perioperative clinical blood transfusion is researched through retrospective analysis, and the purpose is to provide effective reference and guidance when choosing 
Table I. Comparison of the clinical data of the patients in the two groups [n (\%)].

\begin{tabular}{|c|c|c|c|c|}
\hline Data & TEG group $(\mathrm{n}=40)$ & Control group $(\mathrm{n}=34)$ & $\chi^{2}$ or $t$ value & P-value \\
\hline Age (years) & $48.14 \pm 9.16$ & $49.07 \pm 9.86$ & 0.420 & 0.676 \\
\hline Weight (kg) & $62.18 \pm 15.67$ & $63.14 \pm 14.89$ & 0.269 & 0.789 \\
\hline $\operatorname{BMI}\left(\mathrm{kg} / \mathrm{m}^{2}\right)$ & $21.24 \pm 6.24$ & $21.54 \pm 6.17$ & 0.207 & 0.837 \\
\hline Preoperative WBC (x109/1) & $3.16 \pm 2.54$ & $3.08 \pm 2.49$ & 0.136 & 0.892 \\
\hline Preoperative RBC (x10 $12 / 1)$ & $4.07 \pm 1.14$ & $4.15 \pm 1.08$ & 0.308 & 0.759 \\
\hline Preoperative PLT (x109/1) & $167.24 \pm 50.14$ & $172.33 \pm 42.86$ & 0.465 & 0.644 \\
\hline Operation time (min) & $138.14 \pm 34.86$ & $142.27 \pm 38.12$ & 0.487 & 0.628 \\
\hline Sex & & & 0.128 & 0.721 \\
\hline Male & $24(60.00)$ & $19(55.88)$ & & \\
\hline Female & $16(40.00)$ & $15(44.12)$ & & \\
\hline Living environment & & & 0.003 & 0.956 \\
\hline City & $28(70.00)$ & $24(70.59)$ & & \\
\hline Countryside & $12(30.00)$ & $10(29.41)$ & & \\
\hline ASA & & & 0.085 & 0.771 \\
\hline I grade & $19(47.50)$ & $15(44.12)$ & & \\
\hline II grade & $21(52.50)$ & $19(55.88)$ & & \\
\hline Type of operation & & & 0.171 & 0.918 \\
\hline Orthopedic operation & $17(42.50)$ & $14(41.18)$ & & \\
\hline Surgical operation & $16(40.00)$ & $15(44.12)$ & & \\
\hline Other operation & $7(17.50)$ & $5(14.71)$ & & \\
\hline
\end{tabular}

the opportunity of blood transfusion of patient in clinic in the future.

\section{Patients and methods}

General data. Seventy-four patients, who were admitted by the surgical department in the First Hospital of Zibo (Zibo, China) from March 2015 to March 2018, were selected for the study and were retrospectively analysed. There were 43 males and 31 females, aged from 29 to 67 years, and the average age was $48.94 \pm 10.54$ years. Inclusion criteria: All patients had surgery in the hospital; patient condition assessment before anesthesia was in the grade from I to II according to ASA (10); intraoperative blood loss $>1,000 \mathrm{ml}$; patients had complete case data; patients were willing to cooperate with the hospital for the investigation work. Exclusion criteria: Patients had severe organ failure; patients had blood diseases that may affect coagulation function; patients took anticoagulant or antiplatelet drugs in recent 2 months; patients had emergency operations; patients had liver dysfunction; patients were transferred to other hospitals; patients had mental illness.

This study was approved by the Ethics Committee of the First Hospital of Zibo (Zibo, China). Patients who participated in this research had complete clinical data. The signed informed consents were obtained from the patients or the guardians.

Grouping methods. Of the 74 patients, only 34 patients took the traditional coagulation function testing method as the blood transfusion guide during the perioperative period and they were regarded as the control group. The other 40 patients used TEG as the blood transfusion guide during the perioperative period and they were regarded as the TEG group.

Operation methods. The anesthesia induction, intraoperative anesthesia maintenance and operation of the patients in the two groups were completed by the senior clinicians in the hospital, and the operation methods of the same kind of diseases were consistent.

Blood transfusion methods. The control group: Blood gas analysis, the test of coagulation function and blood routine function were carried out respectively before and after the operation (the interval was $1 \mathrm{~h}$ ), when $\mathrm{Hb}<70 \mathrm{~g} / \mathrm{l}$ and Hct $<25 \%, 2$ units of the suspended erythrocytes was added; when PLT $<50 \times 10^{9} \mathrm{U} / 1,1$ unit of platelets was added; $2 \mathrm{~g}$ of fibrinogen was added when fibrinogen was $<1.2 \mathrm{mg} / \mathrm{dl}$. The TEG group: TGE detector (purchased from American Haemoscope company, TEG5000 thromboelastograph) was used for realtime monitoring based on the monitoring of the control group; when $R$ value was $>10 \mathrm{~min}$, it indicated that the clotting factor was reduced, and the frozen plasma $(15 \mathrm{ml} / \mathrm{kg})$ was added; when MA value was $>70 \mathrm{~min}, 1$ unit of platelets was added; when Angle value was $>72$ degrees, $2 \mathrm{~g}$ of fibrinogen was added.

Observation indicators. The coagulation function indicators of the patients in the two groups in $2 \mathrm{~h}$ before the operation and in $24 \mathrm{~h}$ after the operation were: Hb, APTT, Pt, Hct, Plt, Fib; intraoperative transfusion amount and intraoperative blood loss of the patients in the two groups; the condition of blood transfusion of the patients in the two groups during the perioperative 
Table II. The comparison of coagulation function indicators before and after the operation.

\begin{tabular}{|c|c|c|c|c|}
\hline Index & TEG group $(n=40)$ & Control group $(n=34)$ & t value & P-value \\
\hline \multicolumn{5}{|c|}{ In $2 \mathrm{~h}$ before the operation } \\
\hline $\mathrm{Hb}(\mathrm{g} / \mathrm{l})$ & $131.14 \pm 14.01$ & $128.63 \pm 13.42$ & 0.783 & 0.436 \\
\hline APTT(s) & $31.07 \pm 3.15$ & $31.24 \pm 2.95$ & 0.238 & 0.812 \\
\hline $\operatorname{Pt}(\mathrm{s})$ & $11.05 \pm 0.94$ & $10.98 \pm 0.76$ & 0.348 & 0.729 \\
\hline $\operatorname{Hct}(\%)$ & $35.68 \pm 5.14$ & $37.21 \pm 5.06$ & 1.285 & 0.203 \\
\hline Plt (g/l) & $207.63 \pm 66.54$ & $211.08 \pm 70.52$ & 0.216 & 0.829 \\
\hline Fib $(g / l)$ & $3.98 \pm 0.26$ & $3.93 \pm 0.29$ & 0.782 & 0.437 \\
\hline \multicolumn{5}{|c|}{ In $24 \mathrm{~h}$ after the operation } \\
\hline $\mathrm{Hb}(\mathrm{g} / \mathrm{l})$ & $96.14 \pm 7.05^{\mathrm{a}}$ & $95.23 \pm 8.14^{\mathrm{a}}$ & 0.515 & 0.608 \\
\hline APTT(s) & $35.08 \pm 4.66^{\mathrm{a}}$ & $33.87 \pm 5.24^{\mathrm{a}}$ & 1.051 & 0.297 \\
\hline $\operatorname{Pt}(\mathrm{s})$ & $16.23 \pm 2.51^{\mathrm{a}}$ & $15.14 \pm 3.01^{\mathrm{a}}$ & 1.700 & 0.094 \\
\hline $\operatorname{Hct}(\%)$ & $26.96 \pm 6.56^{\mathrm{a}}$ & $27.08 \pm 7.12^{\mathrm{a}}$ & 0.075 & 0.940 \\
\hline Plt (g/l) & $142.37 \pm 69.52^{\mathrm{a}}$ & $146.72 \pm 72.37^{\mathrm{a}}$ & 0.263 & 0.793 \\
\hline Fib $(g / 1)$ & $3.08 \pm 0.49^{\mathrm{a}}$ & $2.96 \pm 0.55^{\mathrm{a}}$ & 0.992 & 0.324 \\
\hline
\end{tabular}

${ }^{\text {a }}<0.050$, compared with the preoperative indicators in the same group.

Table III. The comparison of the condition of the operation.

\begin{tabular}{|c|c|c|c|c|}
\hline Index & TEG group $(n=40)$ & Control group $(n=34)$ & t value & $\mathrm{P}$-value \\
\hline Intraoperative blood loss (ml) & $2,486.12 \pm 654.73$ & $2,514.26 \pm 701.08$ & 0.178 & 0.859 \\
\hline Intraoperative transfusion amount (ml) & $1,577.63 \pm 364.62$ & $2,574.46 \pm 514.63$ & 9.717 & $<0.001$ \\
\hline
\end{tabular}

period: the suspended erythrocyte, fibrinogen, Plt, the condition of plasma use; the clinical results of the patients in the two groups: The occurrence rate of the postoperative rebleeding, the length of hospital stay and mortality.

Statistical methods. The data were analysed and processed by using SPSS 24.0 statistical software (IBM Corp., Armonk, NY, USA); the enumeration data were expressed in the form of a rate; the comparison between the groups was performed by using Chi-square test; the measurement data were expressed as the mean \pm standard deviation and the comparison between the groups was performed by using t-test. $\mathrm{P}<0.05$ was considered to indicate a statistically significant difference.

\section{Results}

Comparison of the general data. The age, weight, BMI, preoperative blood routine indicators, operation time, sex, ASA grade and the type of operation were compared between the two groups, and no significant difference $(\mathrm{P}>0.050)$ was found, indicating that the patients in the two groups were comparable (Table I).

Comparison of coagulation function before and after the operation. When comparing the coagulation function indicators of the patients in the two groups in $2 \mathrm{~h}$ before the operation and in $24 \mathrm{~h}$ after the operation, it was shown that there was no significant difference between the two groups $(\mathrm{P}>0.050)$. However, APTT and Pt of the patients in the two groups both increased when compared with those before the treatment $(\mathrm{P}<0.050)$ and $\mathrm{Hb}$, Hct, Plt and Fib both decreased $(\mathrm{P}<0.050)$ (Table II).

Comparison of the condition of the operation. There was no significant difference when comparing the intraoperative blood loss of the patients in the two groups $(\mathrm{P}>0.050)$, while the intraoperative transfusion amount in the TEG group was $1,577.63 \pm 364.62 \mathrm{ml}$, which was significantly less than the intraoperative transfusion amount in the control group $(2,574.46 \pm 514.63 \mathrm{ml}), \mathrm{P}<0.001$ (Table III).

Comparison of the condition of the blood transfusion. In the TEG group, $4.24 \pm 1.24$ units of the suspended erythrocytes was used during the perioperative period, which was significantly less than that in the control group $(6.27 \pm 1.86$ units, $\mathrm{P}<0.001)$; $1.94 \pm 0.75$ units of Plt was used in the TEG group during the perioperative period, which was significantly less than that in the control group $(3.42 \pm 1.24$ units, $\mathrm{P}<0.001) ; 2.13 \pm 0.83 \mathrm{~g}$ of fibrinogen was used in the TEG group during the perioperative period, which was significantly less than that in the control group $(3.24 \pm 1.22 \mathrm{~g}, \mathrm{P}<0.001) ; 224.63 \pm 41.86 \mathrm{ml}$ of plasma was used in the TEG group during the perioperative period, which was significantly less than that in the control group (427.86 \pm 35.14 ml, $\mathrm{P}<0.001)$ (Figs. 1-4). 


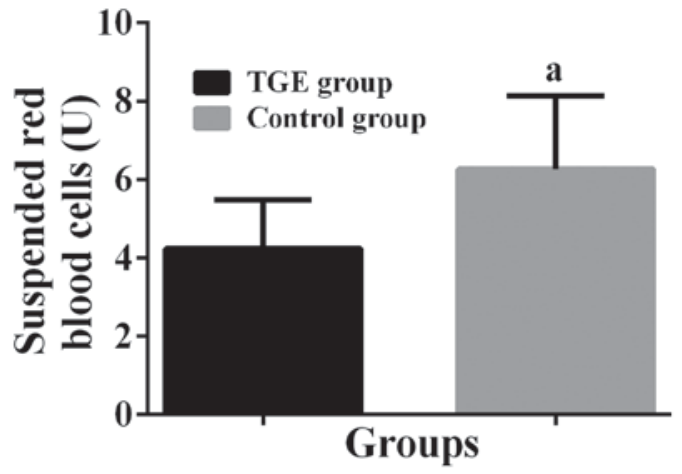

Figure 1. The comparison of the use of the suspended erythrocytes of the patients in the two groups. The amount of the suspended erythrocytes in the control group was significantly higher than that used in the TEG group; ${ }^{a} \mathrm{P}<0.050$, compared with the amount of the suspended erythrocytes used in the TEG group.

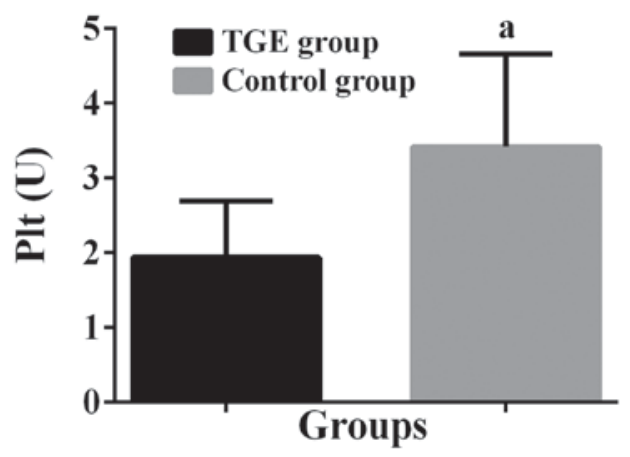

Figure 2. The comparison of the use of Plt of the patients in the two groups The amount of Plt in the control group was significantly higher than that used in the TEG group; ${ }^{\text {a }}<0.050$, compared with the amount of Plt use in the TEG group.

Comparison of the clinical results. The length of hospital stay of the patients in the TEG group was $16.24 \pm 2.16$ days, which was significantly shorter than that in the control group (18.96 \pm 5.62 days), $\mathrm{P}=0.006$; there was no significant difference when comparing the occurrence rate of the postoperative rebleeding and mortality of the two groups $(\mathrm{P}>0.050)$ (Table IV).

\section{Discussion}

Coagulation function is the key to determine the condition of perioperative bleeding of patient, and keeping patient's coagulation function in a stable state is the fundamental solution to reduce the occurrence of operating massive hemorrhage in patients (11). During the operation, traumatic invasive procedures, blood loss in vitro, oxidative reaction in the body and the various aspects of factors could cause coagulopathy in patient (12-14). The blood circulation is a necessary part of the rehabilitation of patient's body; slight damage of coagulation function causes the prolongation of the rehabilitation cycle, and the treatment effect is not good and serious damage of coagulation function endangers patient's life and health (15). In order to keep the patient's blood circulation operating normally, perioperative blood transfusion is necessary and an extremely important part (16). During the process of perioperative

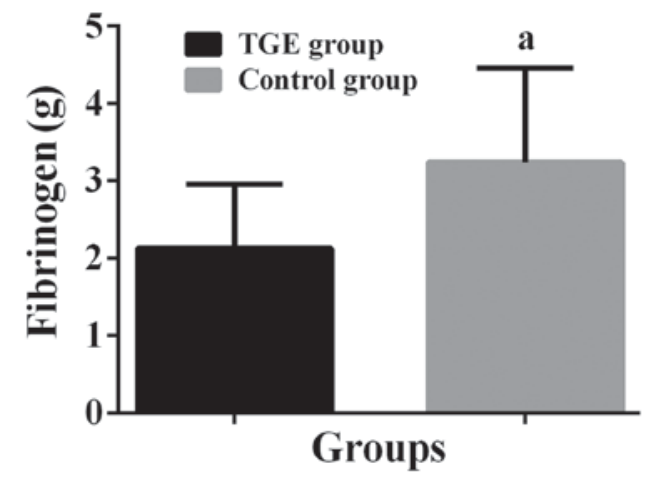

Figure 3. The comparison of the use of fibrinogen of the patients in the two groups. The amount of fibrinogen in the control group was significantly higher than that used in the TEG group; ${ }^{a} \mathrm{P}<0.050$, compared with the amount of fibrinogen used in the TEG group.

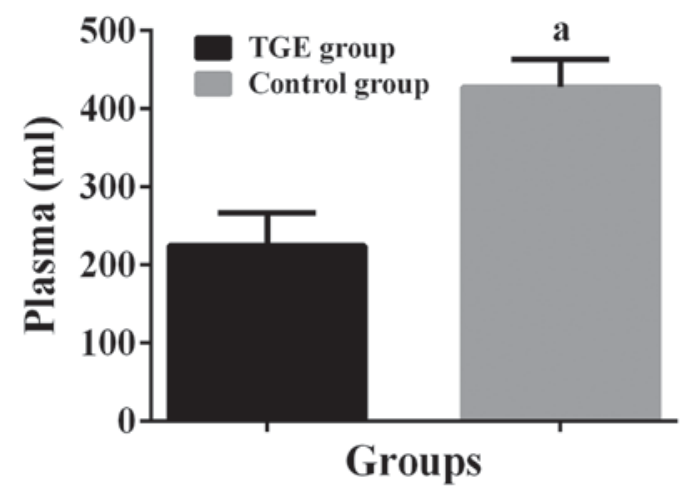

Figure 4. The comparison of the use of plasma of the patients in the two groups. The amount of plasma in the control group was significantly higher than that used in the TEG group; ${ }^{a} \mathrm{P}<0.050$, compared with the amount of plasma used in the TEG group.

blood transfusion, patients may have some symptoms, such as low calcium, high potassium, and $\mathrm{pH}$ imbalance due to the massive loss of clotting factors and platelets and the infusion of erythrocyte suspension, and the anticoagulant infused into the blood may also cause coagulation function becoming abnormal again $(17,18)$. Therefore, how to accurately assess the blood transfusion amount and blood transfusion type of patient during the perioperative period is a research hotspot in clinic. The traditional blood routine and coagulation function have a low detection mobility and their real-time monitoring ability is poor, thereby they cannot meet the clinical accurate judgment for the condition of patient's blood transfusion; TEG is the only effective method to continuously and dynamically monitor the process of blood coagulation when the blood transfusion amount is extremely low $(19,20)$. Not only does it have a good monitoring effect on the changes in cells and plasma, but also have a clear judgment on the generation time of blood clots (21). At present, there are still only a few studies on TEG worldwide and few accurate references, which are on TEG and can be used as a guide in clinic. Therefore, this study aims to prove that the diagnostic value of TEG in the condition of blood transfusion of the patients who are in the perioperative period by comparing TEG and traditional blood coagulation monitoring applied in the condition of blood transfusion of the patients who are in the perioperative period. 
Table IV. The comparison of the clinical results of the patients in the two groups [n (\%)].

\begin{tabular}{lccr}
\hline Index & TEG group (n=40) & Control group (n=34) & $\chi^{2}$ or t value \\
\hline Length of hospital stay (days) & $16.24 \pm 2.16$ & $18.96 \pm 5.62$ & 2.828 \\
Occurrence rate of the postoperative rebleeding & $4(10.00)$ & $7(20.59)$ & 0.006 \\
Mortality & $1(2.50)$ & $1(2.94)$ & 0.202 \\
\hline
\end{tabular}

The results of this study showed that there was no significant difference in the inspection results of coagulation function of the patients in the two groups in $2 \mathrm{~h}$ before the operation and in $24 \mathrm{~h}$ after the operation, suggesting that TEG would not affect the patient's coagulation function, such as the traditional detection method, which was also available for the patients who were in the perioperative period. When comparing the intraoperative blood transfusion amount and intraoperative blood loss in the two groups, it was shown that there was no significant difference in the intraoperative blood loss of the patients in the two groups, but the intraoperative blood transfusion amount in the TEG group was significantly less than that in the control group. Further comparison of the condition of the blood transfusion between the two groups showed that the use of each infusion solution of the patients in the TEG group was significantly lower than that in the control group, which was consistent with the results of Lawson et al (22). The length of hospital stay of the patients in the TEG group was significantly lower than that in the control group, and there was no significant difference when comparing the occurrence rate of the postoperative rebleeding and mortality in the TEG group with those in the control group, suggesting that TEG could make a more accurate judgment on the perioperative blood transfusion of patient. In terms of the reasons, it was considered that during the monitoring process of TEG, the generation time ( $R$ value) of the patient's blood clot was used as the infusion basis of plasma; the maximum amplitude (MA value) of the formation of thrombus was used as the infusion basis of $\mathrm{Plt}$, and the intensity (K value) of fibrinogen was used as the infusion basis of fibrinogen $(23,24)$, which more reasonably and accurately guided the patient's mathematical situation. Compared with the traditional coagulation function test, TEG can infuse the targeted blood products into the patients who are in the perioperative period, and accurately adjust the improved condition of blood coagulation in patient's body according to the quality of the blood transfusion to achieve the purpose of significantly improving the coagulation function of patient. TEG can comprehensively reflect the process, in which the blood clot forms and fiber dissolves in the sample blood, and reflect the interaction between clotting factors and platelets, which has a more accurate judgment for patient's overall coagulation condition (25). Moreover, the generation speed of TEG monitoring results are significantly faster than that of the traditional coagulation function test, which helps to instruct doctors to make timely decision and treatment for the blood transfusion. Since the transfusion condition of the patients in the TEG group was more accurate, it was speculated that this was one of the reasons why the recovery period of the TEG group was shorter than that of the control group. There was no statistical difference in the postoperative rebleeding rate between the two groups, and it was speculated that the reason for this was the experimental error, which was caused by the small sample size; in terms of the actual number of the patients, the patients in the TEG group were significantly less than those in the control group.

The results of this experiment showed that TEG was more suitable for estimating the blood transfusion of a patient who was in the perioperative period when compared with the traditional coagulation function test, but there were still some shortcomings. For example, TEG is a test in vitro, and detecting differences between patient and the internal environment in patient's body may cause errors in the results of coagulation function (e.g., the effects of patient's vascular endothelium and vascular nose, on coagulation function); and the patient usually is in anesthesia during the operation, also patient's body temperature is low, which may have an effect on the results. The test result of TEG for the general coagulation function of patient is better, but it has a weaker ability to distinguish the abnormality in certain coagulation process. Moreover, the number of cases included in this study was small, and the statistical analysis of large data could not be carried out.

In summary, compared with the traditional coagulation function test, TEG is more accurate for estimating the coagulation function of patient, and is more suitable for estimating the condition of blood transfusion of patient in the perioperative period; also, it can shorten the recovery period of patient and it is worthwhile to promote in the clinic.

\section{Acknowledgements}

Not applicable.

\section{Funding}

No funding was received.

\section{Availability of data and materials}

The datasets used and/or analyzed during the current study are available from the corresponding author on reasonable request.

\section{Authors' contributions}

HS and BS conceived the study and drafted the manuscript. JL and LW acquired the data. BS and GS analyzed the data. HS and JL revised the manuscript. All authors revised, read and approved the final manuscript. 


\section{Ethics approval and consent to participate}

This study was approved by the Ethics Committee of the First Hospital of Zibo (Zibo, China). Patients who participated in this research had complete clinical data. The signed informed consents were obtained from the patients or the guardians.

\section{Patient consent for publication}

Not applicable.

\section{Competing interests}

The authors declare that they have no competing interests.

\section{References}

1. Clark NP, Douketis JD, Hasselblad V, Schulman S, Kindzelski AL and Ortel TL; BRIDGE Investigators: Predictors of perioperative major bleeding in patients who interrupt warfarin for an elective surgery or procedure: Analysis of the BRIDGE trial. Am Heart J 195: 108-114, 2018.

2. Paparella D and Whitlock R: Safety of salvaged blood and risk of coagulopathy in cardiac surgery. Semin Thromb Hemost 42: $166-171,2016$.

3. Drolz A, Horvatits T, Roedl K, Rutter K, Staufer K, Kneidinger N, Holzinger U, Zauner C, Schellongowski P, Heinz G, et al: Coagulation parameters and major bleeding in critically ill patients with cirrhosis. Hepatology 64: 556-568, 2016.

4. Kim JL, Park JH, Han SB, Cho IY and Jang KM: Allogeneic blood transfusion is a significant risk factor for surgical-site infection following total hip and knee arthroplasty: A metaanalysis. J Arthroplasty 32: 320-325, 2017.

5. Le Quellec S, Paris M, Nougier C, Sobas F, Rugeri L, Girard S, Bordet JC, Négrier C and Dargaud Y: Pre-analytical effects of pneumatic tube system transport on routine haematology and coagulation tests, global coagulation assays and platelet function assays. Thromb Res 153: 7-13, 2017.

6. Rhee C, Lethbridge L, Richardson G and Dunbar M: Risk factors for infection, revision, death, blood transfusion and longer hospital stay 3 months and 1 year after primary total hip or knee arthroplasty. Can J Surg 61: 165-176, 2018.

7. Hanafy AS, Badawi R, Basha MAA, Selim A, Yousef M, Elnawasany S, Mansour L, Elkhouly RA, Hawash N and Abd-Elsalam S: A novel scoring system for prediction of esophageal varices in critically ill patients. Clin Exp Gastroenterol 10: 315-325, 2017.

8. De Pietri L, Bianchini M, Montalti R, De Maria N, Di Maira T, Begliomini B, Gerunda GE, di Benedetto F, Garcia-Tsao G and Villa E: Thrombelastography-guided blood product use before invasive procedures in cirrhosis with severe coagulopathy: A randomized, controlled trial. Hepatology 63: 566-573, 2016.

9. Abuelkasem E, Lu S, Tanaka K, Planinsic R and Sakai T: Comparison between thrombelastography and thromboelastometry in hyperfibrinolysis detection during adult liver transplantation. Br J Anaesth 116: 507-512, 2016.

10. Marian AA, Bayman EO, Gillett A, Hadder B and Todd MM: The influence of the type and design of the anesthesia record on ASA physical status scores in surgical patients: Paper records vs. electronic anesthesia records. BMC Med Inform Decis Mak 16: 29-38, 2016.

11. Iba T, Gando S, Saitoh D, Ikeda T, Anan H, Oda S, Kitamura N, Mori S, Kotani J and Kuroda Y: Efficacy and bleeding risk of antithrombin supplementation in patients with septic disseminated intravascular coagulation: A third survey. Clin Appl Thromb Hemost 23: 422-428, 2017
12. Rasmussen KC, Højskov M, Johansson PI, Kridina I, Kistorp T, Salling L, Nielsen HB, Ruhnau B, Pedersen T and Secher NH: Impact of albumin on coagulation competence and hemorrhage during major surgery: A randomized controlled trial. Medicine (Baltimore) 95: e2720, 2016.

13. Douketis JD, Wang G, Chan N, Eikelboom JW, Syed S, Barty R, Moffat KA, Spencer FA, Blostein M and Schulman S: Effect of standardized perioperative dabigatran interruption on the residual anticoagulation effect at the time of surgery or procedure. J Thromb Haemost 14: 89-97, 2016.

14. Spahn DR, Spahn GH and Stein P: Indications and risks of fibrinogen in surgery and trauma. Semin Thromb Hemost 42: 147-154, 2016.

15. Gonzalez E, Moore EE, Moore HB, Chapman MP, Chin TL, Ghasabyan A, Wohlauer MV, Barnett CC, Bensard DD, Biffl WL, et al: Goal-directed hemostatic resuscitation of trauma-induced coagulopathy: A pragmatic randomized clinical trial comparing a viscoelastic assay to conventional coagulation assays. Ann Surg 263: 1051-1059, 2016.

16. Yang T, Lu JH, Lau WY, Zhang TY, Zhang H, Shen YN, Alshebeeb K, Wu MC, Schwartz M and Shen F: Perioperative blood transfusion does not influence recurrence-free and overall survivals after curative resection for hepatocellular carcinoma: A Propensity Score Matching Analysis. J Hepatol 64: 583-593, 2016.

17. Pohlman TH, Fecher AM and Arreola-Garcia C: Optimizing transfusion strategies in damage control resuscitation: Current insights. J Blood Med 9: 117-133, 2018.

18. Qiu L, Wang DR, Zhang XY, Gao S, Li XX, Sun GP and Lu XB: Impact of perioperative blood transfusion on immune function and prognosis in colorectal cancer patients. Transfus Apheresis Sci 54: 235-241, 2016.

19. Jiang L, Nick AM and Sood AK: Fundamental principles of cancer biology: Does it have relevance to the perioperative period? Curr Anesthesiol Rep 5: 250-256, 2015.

20. Gary JL, Schneider PS, Galpin M, Radwan Z, Munz JW, Achor TS, Prasarn ML and Cotton BA: Can thrombelastography predict venous thromboembolic events in patients with severe extremity trauma? J Orthop Trauma 30: 294-298, 2016.

21. Cybulska P, Goss C, Tew WP, Parameswaran R and Sonoda Y: Indications for and complications of transfusion and the management of gynecologic malignancies. Gynecol Oncol 146: 416-426, 2017.

22. Lawson PJ, Moore HB, Moore EE, Stettler GR, Pshak TJ, Kam I, Silliman CC and Nydam TL: Preoperative thrombelastography maximum amplitude predicts massive transfusion in liver transplantation. J Surg Res 220: 171-175, 2017.

23. Kreutz RP, Schmeisser G, Maatman B, Schaffter A, Sinha A, von der Lohe E and Breall JA: Fibrin clot strength measured by thrombelastography and outcomes after percutaneous coronary intervention. Thromb Haemost 117: 426-428, 2017.

24. Adler M, Ivic S, Bodmer NS, Ten Cate H, Bachmann LM, Wuillemin WA and Nagler M: Thromboelastometry and thrombelastography analysis under normal physiological conditions - systematic review. Transfus Med Hemother 44: 78-83, 2017.

25. David JS, Imhoff E, Parat S, Augey L, Geay-Baillat MO, Incagnoli $\mathrm{P}$ and Tazarourte $\mathrm{K}$ : Use of thrombelastography to guide posttraumatic hemostatic therapy: More coagulation factor concentrates and less allogenic blood transfusion? Transfus Clin Biol 23: 205-211, 2016 (In French).

This work is licensed under a Creative Commons Attribution-NonCommercial-NoDerivatives 4.0 International (CC BY-NC-ND 4.0) License. 